\title{
A nationwide survey in Germany on fatal asthma and near-fatal asthma in children: different entities?
}

\author{
T. Schmitz*, R. von Kries ${ }^{+}$, M. Wjst ${ }^{\#}$ A. Schuster*
}

A nationwide survey in Germany on fatal asthma and near-fatal asthma in children: different entities? T. Schmitz, R. von Kries, M. Wjst, A. Schuster. (C)ERS Journals Ltd 2000. ABSTRACT: In adults fatal and near-fatal asthma have similar clinical characteristics. Therefore, near-fatal asthma in adults can be used as a model for fatal asthma. A nationwide study on fatal and near-fatal asthma in children $<16$ yrs was performed in order to assess whether, as in adults, near-fatal asthma can be used as a model for fatal asthma.

From 1996 to 1998, all paediatric hospitals and paediatric pulmonologists in Germany were asked to report cases of fatal asthma and near-fatal asthma to a central survey unit (Erhebungseinheit für seltene pädiatrische Erkrankungen in Deutschland (ESPED)) on a monthly basis. All reports were followed by detailed questionnaires.

Sixteen fatal and 45 near-fatal asthma cases were analysed. Fatal asthma patients were older than near-fatal asthma patients. Respiratory tract infections were frequently reported only in near-fatal asthma (47 versus $0 \%)$. The proportion of cases with rapid-type onset (duration of symptoms $\leq 1 \mathrm{~h}$ ) was higher in fatal asthma (53 versus $14 \%$ ). Long-term regular treatment with short acting $\beta_{2}$-agonists was common in both groups, but the use of concomitant inhaled corticosteroids was significantly lower in fatal asthma cases. A high proportion of poor compliance was observed in both groups.

As fatal and near-fatal asthma differ significantly in important clinical aspects, analysis of near-fatal asthma might be of limited value in elucidating the causes of fatal asthma in children.

Eur Respir J 2000; 16: 845-849.

An increase in asthma deaths in children has been reported in different industrialized countries of the world [1]. The American Thoracic Society has recently recommended further investigations into causalities [2]. In near-fatal asthma attacks, information can be obtained from both close family members and the patient who survived the severe asthma attack. In adults, fatal and near-fatal asthma have been found to have similar characteristics, and it has been suggested that the more frequent near-fatal asthma cases be studied to complement insights into the patterns of fatal asthma [3]. Monitoring of increases in near-fatal asthma cases might be used as an early warning system for increases in asthma mortality. Near-fatal asthma cases may add information to case/ control studies of fatal attacks. However, although some factors may increase the risk of both fatal and near-fatal asthma, others may only be crucial to the fatal outcome of a severe attack or vice versa [4]. Even though near-fatal asthma may be a precursor of fatal asthma, the potential limitations of this approach have been discussed [4].

In order to identify similarities and differences between fatal and near-fatal asthma in childhood, a nationwide survey was performed in Germany between 1996 and 1998. The study focused on age, sex, ethnicity, long-term medical care, prescribed medication, compliance, reported clinical type of onset and possible triggering factors (e.g. respiratory tract infections and allergen exposure).

\begin{abstract}
*Dept of Paediatrics, Heinrich Heine University, Düsseldorf, Germany. ${ }^{\#}$ gsfInstitute for Epidemiology, Dept of Molecular Epidemiology, Oberschleißheim, Germany. ${ }^{+}$Institute for Social Paediatrics and Adolescent Medicine, Ludwig-Maximilian University, Munich, Germany.
\end{abstract}

Correspondence: A. Schuster, Dept of Paediatrics, Heinrich Heine Universität, Moorenstr. 5, D-40225 Düsseldorf, Germany. Fax: 492118116441

Keywords: Children

fatal asthma

near-fatal asthma

\section{Received: April 42000}

Accepted after revision August 72000

This study was supported by ALK Scherax, Glaxo Wellcome, Zeneca and Boehringer Ingelheim.

\section{Methods}

The survey was performed in cooperation with the German Surveillance Unit for Rare Paediatric Disorders (Erhebungseinheit für seltene pädiatrische Erkrankungen in Deutschland (ESPED)). This survey unit sends monthly postcards to all paediatric hospitals who report whether or not one of the disorders has been diagnosed. In the present fatal/near-fatal asthma survey, all members of the Society for Paediatric Pulmonology in Germany were included in order to obtain information regarding patients who did not reach a hospital during the acute attack. In total, 487 cards were sent out monthly. The return rate of the cards was 94 $96 \%$. Following a positive reply, a detailed questionnaire was sent to the reporting institution and returned in all cases. If necessary, complete information was obtained by means of a telephone interview.

The 3-yr time period of the present survey was January 1, 1996-December 31, 1998. The case definition was: death or mechanical ventilation (near-fatal attacks) due to symptomatic respiratory obstruction caused by chronic asthma, recurrent wheezy bronchitis or a first asthma attack in children of $<16$ yrs.

The questionnaire asked for the following information: sex, age, ethnicity, medical care and medication prescribed before the time of deterioration, compliance with medication, possible contributing factors (e.g. respiratory tract 
infections, allergen exposure, physical exertion and immunotherapy), and clinical course of the acute attack. Two different types of clinical scenario were distinguished: type 1, characterized by a prolonged period of time between onset of asthma symptoms and death, lasting several hours to several days (slow onset), and type 2 , in which death occurs within $1 \mathrm{~h}$ (sudden onset). In cases of near-fatal asthma, the duration of symptoms was determined from onset of symptoms until intubation for mechanical ventilation.

For statistical analysis, the computer package system SPSS 8.1 (SPSS Inc., Chicago, IL, USA) was used. Numerical variables were compared using Kruskal-Wallis tests. For categorical variables, the chi-squared test and Fisher exact test were used as appropriate. A two sided pvalue of $<0.05$ was considered significant.

\section{Results}

A total of 16 confirmed cases of fatal asthma and 45 of near-fatal asthma in children were analysed (table 1). Three additional cases were excluded because the clinical deterioration could not be unambiguously attributed to asthma, but could alternatively be explained by underlying diseases, i.e. bronchopulmonary dysplasia $(n=2)$ and malformation of the respiratory tract $(n=1)$.

Table 1. - Comparison of fatal and near-fatal asthma cases

\begin{tabular}{|c|c|c|}
\hline & Fatal asthma & $\begin{array}{l}\text { Near-fatal } \\
\text { asthma }\end{array}$ \\
\hline $\begin{array}{l}\text { Subjects } \mathrm{n} \\
\text { Age yrs, months }\end{array}$ & 16 & 45 \\
\hline Age distribution yrs & $12,2(5,4-15,5)$ & $9,6(0,1-15,5)^{*}$ \\
\hline$>0$ and $<5$ & $0 / 16(0)$ & $16 / 45(36)$ \\
\hline$\geq 5$ and $<10$ & $4 / 16(25)$ & $9 / 45(20)$ \\
\hline$\geq 10$ and $<16$ & $12 / 16(75)$ & $20 / 45(44)$ \\
\hline \multicolumn{3}{|l|}{ Type of clinical course } \\
\hline $\begin{array}{l}\text { No information } \\
\text { available }\end{array}$ & $1 / 16(6)$ & $3 / 45(7)$ \\
\hline Type 1 (slow onset) & $7 / 15(47)$ & $36 / 42(86)^{* *}$ \\
\hline Type 2 (rapid onset) & $8 / 15(53)$ & $6 / 42(14)^{* *}$ \\
\hline \multicolumn{3}{|l|}{ Contributing factors } \\
\hline Respiratory infections & $0 / 16(0)$ & $21 / 45(47)^{* * *}$ \\
\hline Others & $3 / 16(19)$ & 6/45 (13) \\
\hline None observed & $13 / 16(81)$ & $19 / 45(40)$ \\
\hline \multicolumn{3}{|l|}{ Regular medication } \\
\hline s.a. $\beta_{2}$-agonist & $10 / 16(63)$ & $21 / 45$ (47) \\
\hline $\begin{array}{l}\text { s.a. } \beta_{2} \text {-agonist plus } \\
\text { concomitant ICS }\end{array}$ & $1 / 10(10)$ & $13 / 21(62)^{* *}$ \\
\hline \multicolumn{3}{|l|}{ Compliance } \\
\hline $\begin{array}{l}\text { No information } \\
\text { available }\end{array}$ & $1 / 16(6)$ & $12 / 45(27)$ \\
\hline Poor compliance & $8 / 15(53)$ & $19 / 33(58)$ \\
\hline $\begin{array}{l}\text { Long-term care by } \\
\text { paediatric asthma } \\
\text { specialist }\end{array}$ & $2 / 16(13)$ & $12 / 45(27)$ \\
\hline
\end{tabular}

Data are presented as absolute values with percentages in parentheses or median (range). s.a: short-acting; ICS: inhaled corticosteroids. *: $\mathrm{p}<0.05 ; * *: \mathrm{p}<0.01 ; * * *: \mathrm{p}<0.001$.
The median age of the 16 patients with fatal asthma $(12,2$ yrs, months (range 5,4-15,5)) was higher than that of the near-fatal asthma patients $(9,6$ yrs, months (range $0,1-15,5))(\mathrm{p}<0.05)$. None of the 16 fatal asthma cases was $<5 \mathrm{yrs}$, and $12(75 \%)$ were $\geq 10$ and $<16$ yrs, whereas nearfatal asthma cases were more equally distributed across all age groups (table 1).

In eight fatal asthma patients, the clinical picture of the acute attack followed a type 2 pattern (sudden onset); in seven patients, there was a type 1 pattern (slow onset); and, in one patient, no information on the clinical course was available. In near-fatal asthma, the type 2 pattern was only observed in six of 42 cases (type 1 pattern in 36 of 42 cases); in three cases, no information was available. The difference in frequency of the observed clinical course patterns could not be explained by chance alone $(p<0.01)$. If the age cut-off was performed at 5 yrs, i.e., if the youngest children that were affected by near-fatal asthma alone were excluded, the difference between fatal and nearfatal asthma regarding frequency of clinical patterns was still significant $(p<0.05)$. Nine of the 16 asthma deaths occurred outside hospitals. Rapid clinical onset was far more pronounced in these cases (seven of nine) than in those that reached a hospital (one of seven). Otherwise, asthma deaths outside hospitals did not differ in their characteristics from those observed in hospitals.

In the vast majority of fatal asthma cases, no possible contributing factor could be identified ( $81 \%)$. In particular, there were no cases of fatal asthma with a diagnosis of respiratory tract infection. Exposure to allergens and severe physical exertion were considered possible triggering factors in one and two cases, respectively. In contrast, in almost half of the near-fatal asthma cases (21/45 (47\%)), respiratory tract infections were reported as a contributing factor. In near-fatal asthma patients, other contributing factors were mentioned only rarely (allergen exposure $n=3$, physical exertion $n=1$, bronchoscopy $n=1$ and anaesthesia $\mathrm{n}=1$ ). The two groups differed significantly regarding contributing factors $(\mathrm{p}<0.01$ for none versus any; $\mathrm{p}=0.001$ for respiratory tract infections alone) (table 1). The difference between fatal and near-fatal asthma regarding respiratory tract infections remained significant if only patients of $>5$ yrs were considered $(\mathrm{p}<0.05)$.

The male:female ratio was 10:6 in fatal asthma and 22:23 in near-fatal asthma. There were only Caucasian patients in the fatal asthma group. In near-fatal asthma, all patients were Caucasian except for one from Vietnam and one from Morocco. Seasonal variation of the cases was not observed.

In both groups, there was a high proportion of patients who had been prescribed regular short-acting $\beta_{2}$-agonists prior to the acute deterioration: 10/16 (63\%) fatal asthma cases and 21/45 (47\%) near-fatal asthma cases. However, near-fatal asthma cases on regular short-acting $\beta_{2}$-agonists had more frequently undergone concomitant treatment with inhaled corticosteroids (ICSs) than fatal asthma cases on regular short-acting $\beta_{2}$-agonists: 13 of 21 of the nearfatal asthma cases compared to one of 10 of the fatal asthma cases $(p<0.01)$ (table 1$)$. Two of the fatal asthma cases had received regular short-acting $\beta_{2}$-agonists alone, six had been prescribed regular short-acting $\beta_{2}$-agonists with concomitant sodium cromoglycate (SCG) alone, and four had received regular short-acting $\beta_{2}$-agonists with concomitant theophylline. Two near-fatal asthma cases 
had been prescribed regular short-acting $\beta_{2}$-agonists alone, five near-fatal asthma cases on regular short-acting $\beta_{2}$-agonists received concomitant SCG and 10 concomitant theophylline. The short-acting $\beta_{2}$-agonists used on a regular basis were salbutamol (19 of 31), reproterol (four of 31), terbutaline (one of 31), and fenoterol (seven of 31 , three of them fatal and four near-fatal asthma).

Altogether, four fatal asthma patients had undergone long-term treatment with ICS, five with theophylline and seven with SCG. Fifteen (33\%) near-fatal asthma patients had been prescribed regular ICS medication; one had received oral steroids. Thirteen near-fatal asthma patients had used theophylline, and 11 had received prescriptions for SCG. Two fatal and two near-fatal asthma patients had been treated with long-acting $\beta_{2}$-agonists (formoterol or salmeterol).

In patients with available data on compliance, noncompliance was reported to be a long-term problem in eight of $15(53 \%)$ fatal asthma patients and in 19 of 33 $(58 \%)$ near-fatal asthma patients. Two of the fatal asthma patients were known to overuse $\beta_{2}$-agonists excessively (information given spontaneously by reporting institution in reply to questionnaire point on compliance problems).

In both groups, only a few individuals had consulted a specialized paediatric asthma centre in the past, namely two of the 16 fatal asthma patients and 12 of the 45 nearfatal asthma patients.

\section{Discussion}

In the present study, fatal and near-fatal asthma cases were analysed retrospectively to determine whether nearfatal asthma might be useful as a model for fatal asthma in order to improve understanding of and consequently prevent asthma deaths in children. For the purpose of the study of aetiologies, the advantage of near-fatal asthma is its higher prevalence and the possibility of obtaining information on the clinical course from both the patients who survived the severe asthma attacks and their families. BEASLEY et al. [4] suggested that monitoring of the time trends in near-fatal asthma may serve as a "warning system" for the time trends of fatal asthma, and that some near-fatal asthma cases might represent "survivors" of a potentially fatal asthma attack.

Although the return rate in the monthly surveillance was high and a $100 \%$ return rate of subsequent questionnaires was achieved, underreporting of fatal and near-fatal cases must be considered. Unfortunately, there is no adequate source available to ascertain the completeness of the asthma death figures in the present study. Death statistics in Germany are processed by so-called lay-designators who use physicians' notes on death certificates to fill in a code for the cause of death on a separate form. It is not possible to back-control death statistics, and the accuracy of statistics of asthma deaths in Germany has not been investigated to date. Some such investigations in other countries have shown a conspicuous lack of diagnostic specificity [5]. The number of asthma deaths $(n=31)$ given by official death statistics during 1996-1998 in children of $<16$ yrs suggests underreporting of asthma deaths in the present study. However, even though some patients might have been referred to adult medical hospitals and thus escaped surveillance, this would not account for the differential ascertainment of fatal and near-fatal cases. Since within paediatric hospitals both near-fatal and fatal asthma are equally exceptional, it is likely that both conditions are reported with equally high probabilities. Children who did not reach a paediatric hospital during their fulminant attack might systematically have escaped ascertainment in the present surveillance scheme. This bias, however, does not appear very likely in the face of the already high number of type 2 cases of fatal asthma observed in the present study, most of which (seven of eight) occurred outside hospital.

The following features were similar in fatal and nearfatal asthma: ratio of males to females, high rate of regular short-acting $\beta_{2}$-agonists use, and poor compliance. However, the two groups were significantly different regarding mean age, proportion of rapid onset pattern cases, possible triggering factors, and underuse of ICSs in patients on $\beta_{2^{-}}$ agonists.

These findings are in contrast to a report by CAMPBELL et al. [3], who observed that fatal and near-fatal asthma cases in adults have mainly similar characteristics. In that study, numerical, but not significant, differences were only found with respect to age, sex and concurrent medical conditions. These authors concluded that the differences may have appeared by chance and that near-fatal asthma might be a suitable model for fatal asthma.

One remarkable difference between fatal and near-fatal asthma in the present study is the proportion of the two distinct types of onset (type 2 versus type 1), as assessed by clinical observations. Different autopsy findings in deaths due to type 1 and 2 (e.g. infiltration of the airway submucosa with eosinophils versus neutrophils), respectively, might indicate different underlying mechanisms of pathophysiology [6]. If this were true, fatal and near-fatal asthma might indeed be different entities since type 2 was predominant only in fatal and not in near-fatal asthma. Naturally, the present categorization could only be based on clinical assessment, as bronchial biopsy in the acute situation in children with near-fatal asthma is considered unethical. The higher proportion of type 2 cases in fatal asthma has also been found in the American study on fatal and near-fatal asthma in adults of STRUNK et al. [7].

LEMANSKE and LARSEN [8] suggested that respiratory tract infections represent a risk factor for fatal as well as for near-fatal asthma. Although $47 \%$ of the present nearfatal asthma cases were accompanied or triggered by respiratory tract infections, no infections were reported in the fatal cases. Since this information was explicitly asked for in the questionnaire, it is likely to be equally valid for fatal and near-fatal asthma. Hence, from the present data, respiratory tract infections do not appear to represent a risk-factor for fatal asthma attacks. In $81 \%$ of the fatal asthma patients, no possible contributing factor was identified. The high proportion of rapid onset cases in this group means that, in most of these cases, the observation time was short, and symptoms of respiratory tract infection might not have been noticed at that time. Hence the possibility that some of these cases with no observed contributing factor involved as-yet asymptomatic respiratory tract infections cannot be excluded.

In the present study, cases representing the whole paediatric patient group were analysed. Therefore, infants 
were included in the analysis. This policy causes heterogeneity of the study population. However, differences regarding observed contributing factors and clinical type of onset remained significant even when the age cut-off was raised to 5 yrs.

The authors' hypothesis of different entities is also supported by the age differences found: fatal asthma cases were significantly older than near-fatal ones, and $75 \%$ of fatal asthma cases were teenagers aged 10-15 yrs. A high proportion of teenagers with paediatric fatal asthma has been reported previously by STRUNK [9] and KRAVIS and KOLSKI [10]. They speculated that hormonal and psychosocial changes at that age might interfere with a deteriorating course of the disease. STRUNK [9] suggested that noncompliance might be a major problem in teenagers. Smoking should also be considered a possible triggering factor in asthmatic teenagers.

In adults, regular use of short-acting $\beta_{2}$-agonists has been shown to be associated with deterioration of asthma control [11], and even with an increased risk of fatal and near-fatal asthma [12, 13]. Fenoterol, in particular, has been observed to be a possible cause of an asthma mortality epidemic in New Zealand [14]; in the present study, the use of fenoterol was found only in a small number of cases. The use of ICSs has been associated with a decreased risk of asthma death $[15,16]$. Regular treatment with short-acting $\beta_{2}$-agonists, identified as a major risk-factor, at least in adults, was prescribed in $51 \%$ of cases in the present study. Here, the rapid onset of fatal asthma in the absence of identifiable trigger factors in children dependent on high doses of $\beta_{2}$-agonists might be indicative of markedly increased airway hyperresponsiveness with the propensity for sudden severe bronchoconstriction. Most of the patients on regular short-acting $\beta_{2}$-agonists received these solely or in combination with SCG alone. Near-fatal asthma patients on regular shortacting $\beta_{2}$-agonists received significantly more, often concomitant, ICS treatment than fatal asthma patients on regular short-acting $\beta_{2}$-agonists. Hence undertreatment with ICSs was more pronounced in fatal asthma, which is in accordance with the aforementioned results in adults. Only 14 of the 61 patients (fatal and near-fatal asthma combined) had consulted a paediatric asthma specialist, and most of the asthma deaths were associated with prescriptions contradicting international guidelines (e.g. overuse of $\beta_{2}$-agonists and underuse of ICSs) [17]. Nevertheless, thus far, whether deaths might have been preventable can only be speculated upon. Further studies on fatal and near-fatal asthma with additional population denominator data on asthma care of children in specialized centres or elsewhere might provide further evidence.

In summary, even though there were some similarities between fatal and near-fatal asthma cases, significant differences in important clinical aspects were observed, suggesting that fatal and near-fatal asthma are different entities. Future research should elucidate which strategies for prevention are needed in the two scenarios.

\footnotetext{
Acknowledgements. The authors especially acknowledge the constant help of Mrs. Heinrich, secretary of the Erhebungseinheit für seltene pädiatrische Erkrankungen in Deutschland
}

(ESPED) office in Düsseldorf, Germany. The authors would like to thank all the reporting physicians who helped through their cooperation in collecting the data for the present study: Wörle, Dr. M. Kratz, Illing, Dr. Nassal, Olgahospital, Stuttgart; Dr. Rütschle, Kinderkrankenhaus St Annastift, Ludwigshafen; Dr. W. Park, Dr. Müller, Klinikum Kempten-Oberallgäu; Dr. T. Lennert, Universitätsklinikum Benjamin Franklin, Kinderklinik, Berlin; Dr. R. Seidler, Stadtkrankenhaus, Cuxhaven; Professor Ch. Rieger, St Josef-Hospital, Bochum; Dr. R. Künzel, Städtisches Klinikum St Georg, Kinderklinik Abtnaundorf, Leipzig; Dr. Rheinhold, Dr. Ries, Kinderklinik, Dr. HorstSchrnidt-Kliniken, Wiesbaden; Dr. G. Krandick, Kinderklinik und Poliklinik, Klinikum rechts der Isar, TU München; Dr. Josten, St ElisabethKrankenhaus, Kinderabteilung, Neuwied; Dr. W. Zimmermann, Abteilung für Kinder- und Jugendmedizin, Kreiskrankenhaus Eutin; Dr. Nicolai, Dr. van Haunersches-Kinderspital, Munich; Dr. Kusenbach, Dr. Böhla, Kinderklinik der RWTH Aachen; Dr. Buchkremer, Städtische Kliniken Frankfurt am Main-Höchst; Dr. K. Heidenreich, Kinderstation, Kreiskrankenhaus Köthen; Dr. Göbel, Dr. Kodsi, DRK Kinderklinik Siegen; Dr. Fischer, Dill-Kliniken, Kinderklinik, Dillenburg; Ch. Buck, Universitätsklinik Ulm; Dr. von Klinggräff, Dr. Waack, Städt. Kinderklinik, Kiel; Dr. Avenarius, M. Gleißner, Otto-von-Guerike Universität, Zentrum fur Kinderheilkunde, Magdeburg; W.F. Baum, Martin-Luther Universität, Klinik für Kinderheilkunde, Halle; A. Schnelke, Klinik St Hedwig, Regensburg; Dr. Pallacks, Klinikum Memmingen; Dr. Schametzky, Diakoniekrankenhaus, Rotenburg; Professor Trefz, Dr. Schneider, Kinderklinik, Kreiskrankenhaus Reutlingen; Dr. Lüders, Kinderstation, Kreiskrankenhaus Bad Hersfeld; Dr. Verbeek, Kinderklinik, Kreiskrankenhaus Zittau; Dr. Steiner, Kreiskrankenhaus, Kinderklinik, Rendsburg; Dr. Singer, Kinderklinik der Universität, Göttingen; Dr. K. Kruse, Dr. Reiss, Kinderklinik, Medizinische Universität zu Lübeck; Dr. Dalitz, Universitätskinderklinik Leipzig; Dr. Hölscher, Kinderklinik, Lukaskrankenhaus, Neuss; Dr. Schnäder, Dr. Jäger, Klinikum der Johenn Wolfgang Goethe Universität, Zentrum für Kinderheilkunde, Frankfurt; Dr. Devenge, Dr. Licht, Klinik und Poliklinik für Kinderheilkunde, Universitätsklinik, Cologne; Dr. R. Ude, Kinderklinik, Klinikum Bernburg; Dr. Henzler le Boulanger, Dr. Seeber, Kreiskrankenhaus Lörrach; Dr. Oßwald, Kinderklinik, Hegau-Klinikum, Singen; Dr. Rauch, Kinderklinik, Klinikum Bayreuth; Dr. Buschmann, Klinikum des Philipps-Universität, Zentrum für Kinderheilkunde, Marburg; Dr. Ertelt, Allgemeines Krankenhaus, Kinderklinik St Nikolaus, Viersen; Dr. Eichhorn, Klinikum Ludwigsburg; Dr. Fangerau, Zentralkrankenhaus, Prof-Hess-Kinderklinik, Bremen; Dr. Ludwig, Dr. Langpehr, Pädiatrische Abteilung, Kreiskrankenhouse, Freudenstadt; Dr. Niggemann, Kinderklinik Charité, Humboldt-Universität/Virchow-Klinikum, Berlin; Dr. Schreyer, Städt. Klinikum, Kinderklinik, Weiden; Dr. Stoll, Kreiskrankenhaus Bad Salzungen; Dr. Derbacher, Klinikum Fürth; Schöls, Kinderklinik der Heinriche Heine Universität Düsseldorf; Dr. Prosch, Dr. Steppberger, Klinikum Uckermark, Kinderklinik, Schwedt an der Oder; Dr. Gröber, Kinder- und Jugendmedizinische Klinik, Klinikum Lippe-Detmold $\mathrm{GmbH}$; Dr. Lingenhauber, Allgemeines Kreiskrankenhaus, Hamburg; A. Jacobs, Marienhospital, Wesel; Dr. Knoop, Kinderkrankenhaus Riehl, Cologne. 


\section{References}

1. Burr ML, Limb ES, Andrae S, Barry DMJ, Nagel F. Childhood asthma in four countries: a comparative survey. Int J Epidemiol 1994; 23: 341-346.

2. American Thoracic Society. Update: future directions for research on diseases of the lung. Am J Respir Crit Care Med 1998; 158: 320-334.

3. Campbell DA, McLennan G, Coates JR, et al. A comparison of asthma deaths and near-fatal asthma attacks in South Australia. Eur Respir J 1994; 7: 490-497.

4. Beasley E, Pearce N, Crane J. Use of near fatal asthma for investigating asthma deaths. Thorax 1993; 48: 10931094.

5. Berril WT. Is the death rate from asthma exaggerated? BMJ 1993; 306: 193-194.

6. Sur S, Crotty TB, Kephart GM, et al. Sudden-onset fatal asthma. Am Rev Respir Dis 1993; 148: 713-719.

7. Strunk RC, Nicklas RA, Milgrom H, Ikle D. Fatal and near-fatal asthma questionnaire: prelude to a national registry. J Allergy Clin Immunol 1999; 104: 763-768.

8. Lemanske RF, Larsen GL. Fatal asthma in children. In: Sheffer AL, ed. Fatal Asthma. Lung Biology in Health and Disease. Vol. 115. New York, Marcel Dekker, Inc., 1998; pp. 347-362.

9. Strunk RC. Asthma deaths in childhood: identification of patients at risk and intervention. $J$ Allergy Clin Immunol 1987; 80: 472-477.

10. Kravis LP, Kolski GB. Asthma mortality in children: a 16-years experience at Children's Hospital of Philadelphia. NER Allergy Proc 1986; 7: 442-447.

11. Sears MR, Taylor DR, Print CG, et al. Regular inhaled beta-agonist treatment in bronchial asthma. Lancet 1990; 336: 1391-1396.

12. Spitzer WO, Suissa S, Ernst P, et al. The use of $\beta_{2^{-}}$ agonists and the risk of death and near death from asthma. N Engl J Med 1992; 326: 501-506.

13. Ernst P, Habbick B, Suissa S, et al. Is the association between inhaled beta-agonist use and life threatening asthma because of confounding by severity? Am Rev Respir Dis 1993; 148: 75-79.

14. Pearce N, Beasley R, Crane J, Burgess C, Jackson R. End of New Zealand asthma mortality epidemic. Lancet 1995 ; 345: 41-44.

15. Ernst P, Spitzer WO, Suissa S, et al. Risk of fatal and near-fatal asthma in relation to inhaled corticosteroid use. JAMA 1992; 268: 3462-3464.

16. Suissa S, Ernst P. Optical illusion from visual data analysis: example of the New Zealand asthma mortality epidemic. J Clin Epidemiol 1997; 50: 1079-1088.

17. Warner JO, Naspitz CK, Cropp GJA, and the International Asthma Consensus Group. Third international pediatric consensus statement on the management of childhood asthma. Pediatr Pulmonol 1998; 25: 1-17. 